\title{
Efficacy of Unipedicular Baloon Kyphoplasty for Treatment of Multiple Myeloma Vertebral Lesions
}

\author{
Giovanni Andrea La Maida, Francesco Sala, Giovanna Callea, Dario Capitani, Saurabh Singh \\ Department of Orthopaedics, Niguarda Hospital, Milan, Italy
}

Study Design: A retrospective cohort study.

Purpose: To analyze differences in between the unipedicular vs. bipedicular balloon kyphoplasty for the treatment of multiple myeloma lesions.

Overview of Literature: Both vertebroplasty and kyphoplasty are reported to be effective for the treatment of vertebral compression fractures in multiple myeloma patients. Kyphoplasty is often performed with a bipedicular approach while ver tebroplasty with a monopedicular approach. Monopedicular kyphoplasty is investigated as a viable surgical technique alter natively in comparison with the bipedicular method.

Methods: We performed 37 vertebral body augmentation procedures, 18 vertebroplasty (group A) and 19 kyphoplasty, 9 unipedicular approaches (group B1) and 10 bipedicular approaches (group B2), on 14 patients affected by multiple myeloma with a mean clinical and radiographic follow up of more than 12 months.

Results: Both kyphoplasty techniques lead to a better postoperative improvement of the vertebral height and kyphotic deformity if compared with the vertebroplasty, with a statistical significance for the body height restoration only $(p=$ 0.0066). The unipedicular and the bipedicular kyphoplasty have similar results in term of kyphotic deformity correction and height restoration. The $85.7 \%(12 / 14)$ of the patients had an immediate improvement of the pain and no difference between the vertebroplasty and kyphoplasty groups were observed regarding the pain. We observed a $24.3 \%$ of cement leakage in all groups with no clinical symptoms and noticed that the risk of extravasations was higher in multilevel treatment, in bipedicular kyphoplasty procedures and in patients not treated previously with a bone marrow transplant.

Conclusions: Both vertebroplasty and kyphoplasty are effective in treating vertebral compression fracture due to multiple myeloma. Unipedicular kyphoplasty could give equivalent results as with bipedicular kyphoplasty in multilevel disease, aiming only to restore the sagittal alignment of the spine and the height of the vertebral body especially at the thoracolumbar spinal segment.

Key Words: Unipedicular, Kyphoplasty, Vertebroplasty, Multiple myeloma

\section{Introduction}

Multiple myeloma (MM) is a neoplastic disease, with an incidence of 2 to 3 per 100,000 among the general population.
MM is characterized by the accumulation of malignant plasma cells in the bone marrow leading to impaired haematopoiesis and bone disease, which includes mainly lytic lesions, pathological fractures, hypercalcemia and osteoporosis. It is a tumour of B-cell origin that causes the resorption of bone by osteolytic lesions resulting in bone

Received Dec 31, 2010; 1st Revised Apr 8, 2011; Accepted Apr 14, 2011

Corresponding author: Saurabh Singh, MS, MCh, AO Fellow

Department of Orthopaedics, Niguarda Hospital, Piazza Ospedale Maggiore 3, 20162 Milan, Italy

Tel: +39-0264442541/2990, Fax:+39-0264442392, E-mail: saurabhrpsingh@ gmail.com 
pain and pathological fractures.

Incidence of bone involvement at presentation varies from $70 \%$ to $100 \%$ of patients [1] with a vertebral involvement of about $60 \%$ at time of diagnosis [2].

Vertebral compression fractures are often present in these patients and are cause of considerable morbidity including pain, decreased mobility, spinal deformities and neurological complications in few cases.

The treatment of MM includes chemotherapy and radiotherapy to control the disease progression, biphosphonates to reduce bone resorption and analgesics for the invalidating pain. The conservative treatment for vertebral fractures in MM include bed rest, analgesics and bracing but in some cases it could be of limited use because of the progressive spinal deformity and its invalidating consequence especially for the pulmonary function.

Vertebral augmentation by using polimethylmetacrylate could be a good treatment option in patients not responding to the conservative treatment or in whom the kyphotic deformity is progressive.

In 1987, Galibert et al. [3] reported a preliminary experience in the treatment of a vertebral angioma by percutaneous acrylic vertebroplasty, while in the 1990s kyphoplasty was developed in order to restore the vertebral body height and to reduce the kyphotic deformity often present in multiple vertebral compression fractures.

The major advantage of kyphoplasty over vertebroplasty is the possibility to restore vertebral height to a certain degree and fewer chances of cement leakage, but vertebro- plasty have lower surgical time for a single level and less cost of procedure.

Kyphoplasty, with its balloon tamp, lead to a creation of a cavity into the vertebral body that is easily filled with a low pressure cement, with the consequence of a partial restoration of the body height and correction of kyphosis with a lower risk of cement extravasations whereas unipedicular technique has recently gain popularity in treatment of osteoporotic vertebral fractures.

Both the procedures can be successfully used in patients affected by vertebral compression fractures due to a osteoporosis or lytic lesions, and several authors have reported good results with relatively low complication rates in multiple myeloma [1,4-6]. Present study tries to compare the efficacy and effectivness of surgical technique for unipedicular baloon kyphoplasty in regard to vertebroplasty.

\section{Materials and Methods}

From November 2005 to May 2008 we performed 37 consecutive vertebroplasty and kyphoplasty procedures in 14 patients with MM affected by one or more vertebral compression fractures. There were 8 men and 6 women, with a mean age of 63 years (range, 48 to 81 years).

All patients were referred from the haematology unit of the Hospital and they were strictly followed by the haematologist for the further management.

All patients had an X-ray, magnetic resonance imaging (MRI), percutaneus biopsy and all relevant investigations

Table 1. Patients demographics and clinical characteristics

\begin{tabular}{|c|c|c|c|c|c|c|c|}
\hline Patient No. & Sex & Age (yr) & Myeloma protein & Bone marrow transplant & $\begin{array}{l}\text { Vertebroplasty } \\
\text { (unipedicular) }\end{array}$ & $\begin{array}{r}\text { Kyphoplasty } 1 \\
\text { (unipedicular) }\end{array}$ & $\begin{array}{c}\text { Kyphoplasty } 2 \\
\text { (bipedicular) }\end{array}$ \\
\hline 1 & M & 48 & IgG kappa & Yes (allo) & - & - & $\mathrm{T} 12, \mathrm{~L} 1, \mathrm{~L} 2$ \\
\hline 2 & $\mathrm{~F}$ & 60 & IgG lambda & Yes (auto) & - & L1 & $\mathrm{L} 4$ \\
\hline 3 & $\mathrm{~F}$ & 73 & IgG kappa & No & - & & L4 \\
\hline 4 & M & 58 & IgG lambda & Yes (auto) & L2, L3 & & $\mathrm{T} 12$ \\
\hline 5 & M & 64 & IgG kappa & Yes (auto) & - & - & $\mathrm{T} 12$ \\
\hline 6 & M & 67 & IgG kappa & No & $\mathrm{T} 10, \mathrm{~T} 11, \mathrm{~T} 12, \mathrm{~L} 1, \mathrm{~L} 2$ & - & - \\
\hline 7 & $\mathrm{~F}$ & 81 & IgG lambda & No & $\mathrm{T} 10, \mathrm{~T} 12$ & $\mathrm{~T} 11$ & - \\
\hline 8 & $\mathrm{~F}$ & 60 & - & Yes (auto) & T9, L2 & L3 & L1 \\
\hline 9 & M & 72 & IgG kappa & No & - & - & $\mathrm{T} 12$ \\
\hline 10 & M & 49 & IgG kappa & Yes (allo) & $\mathrm{T} 8, \mathrm{~T} 10$ & T7-T9 & - \\
\hline 11 & M & 61 & IgG lambda & Yes (auto and allo) & - & - & L4 \\
\hline 12 & M & 65 & - & No & L1-L2 & - & - \\
\hline 13 & $\mathrm{~F}$ & 64 & - & No & L1 & T12-L2 & - \\
\hline 14 & $\mathrm{~F}$ & 65 & - & No & $\mathrm{T} 11-\mathrm{T} 12$ & L1-L2 & - \\
\hline
\end{tabular}

M: Male, F: Female. 
preoperatively. Indication for vertebral augmentation was the presence of a symptomatic vertebral fracture, without neurological deficit and a positive MRI signal.

The surgical procedure was always done in operating room under general anaesthesia and under fluoroscopic guidance.

All patients had one to five levels treated with a total amount of 37 levels, 9 patients underwent 18 levels vertebroplasty procedures and 12 patients had 19 levels kyphoplasty procedures. Seven patients had both the vertebroplasty and kyphoplasty procedures on different levels.

The augmentation procedures were always done with a transpedicular approach and in particular vertebroplasty was done with the monoportal technique in all cases. Kyphoplasty was done with a unipedicular approach in 9 levels (Fig. 1) and in bipedicular approach in 10 (Fig. 2). The treated levels ranged from $\mathrm{T} 7$ to $\mathrm{L} 4$, with the majority $(67.5 \%)$ at the thoraco-lumbar junction $(\mathrm{T} 11, \mathrm{n}=2 ; \mathrm{T} 12, \mathrm{n}$ $=9 ; \mathrm{L} 1, \mathrm{n}=7 ; \mathrm{L} 2, \mathrm{n}=7)$.

Ten patients (10/14) had an $\operatorname{IgG}$ myeloma protein ( $\operatorname{IgG}$ kappa, $n=6$; $\operatorname{IgG}$ lambda, $n=4)$ and seven patients $(7 / 14)$ had a bone marrow transplantation (autoplastic in 5 and alloplastic in 2). A patient had both the autologous and alloplast transplant because of the failure of the first one. Demographic and clinical characteristics of the 14 patients are listed in Table 1.

Patients were followed for clinical and radiographic assessment at $+1,+30,+90,+180$ days and every year after the surgical procedure. The pain was assessed by using the visual analogue scale (VAS) preoperatively and at each follow up visit. The scale ranged from 0 to 10 , with 0 for no pain and 10 for the maximum pain.

The follow up vary from a minimum of 10 months to a maximum of 3 years, with a mean period of more than 12 months.

Statistical analysis was done on the clinical and radiographic data by using the Student's $t$-test to assess the significance of pre- and post-operative surgical differences. $p$ $<0.05$ was considered to be statistically significant.

\section{Results}

Thirty seven levels were treated in 14 patients (mean, 2.6 levels per patient; range, 1 to 5 levels), with 18 vertebro-

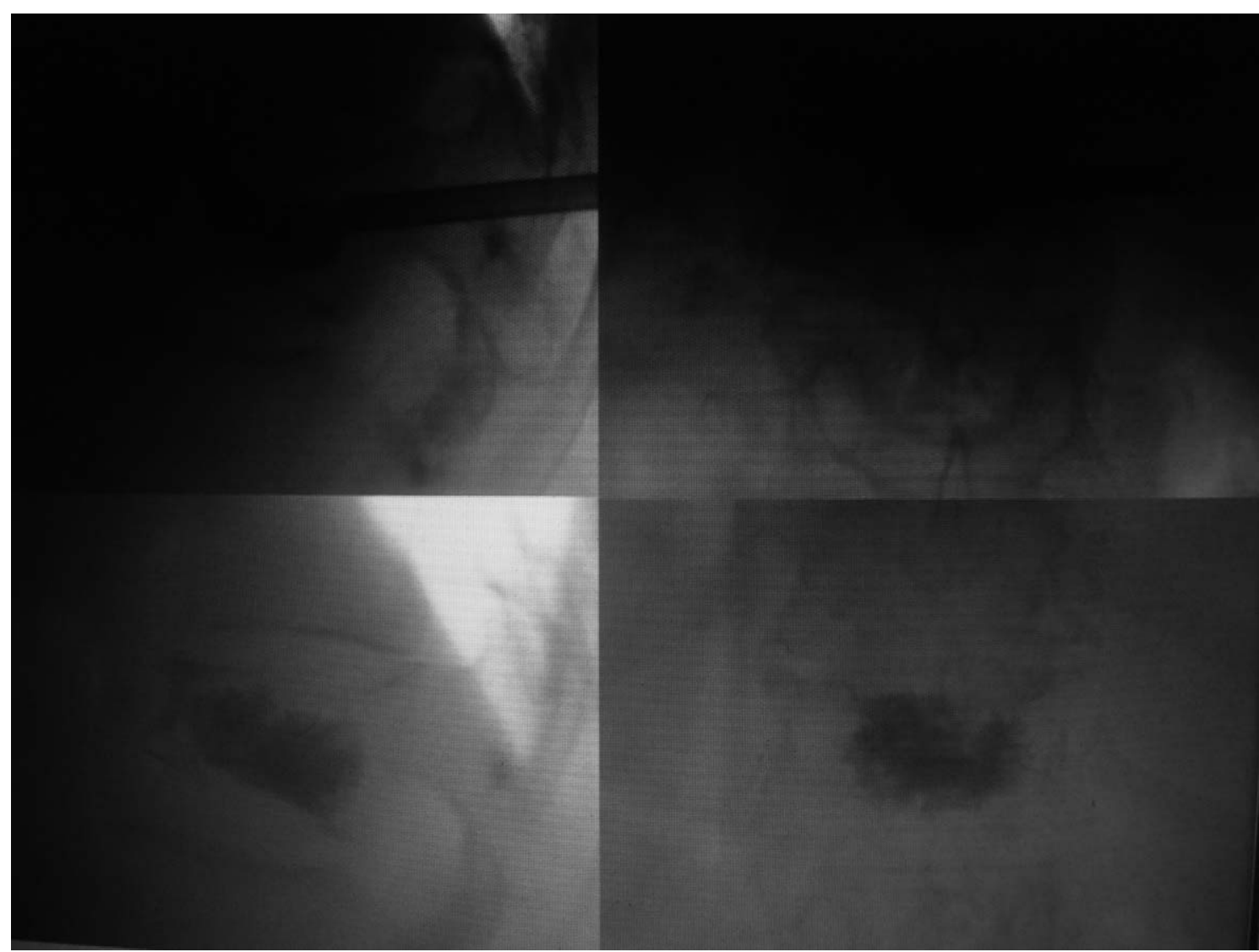

Fig. 1. Intraoperative X-rays of unipedicular kyphoplasty. 
plasty procedures and 19 kyphoplasty procedures with uniand bipedicular approach.

There were 18 thoracic levels and 19 lumbar levels treated, with a $43.2 \%$ of the levels (16/37) localized in T12-L1. There was an equal distribution of the thoracic (10/18) and lumbar (8/18) levels in the vertebroplasty group while there was a high distribution in the lumbar spine (11/19) for the kyphoplasty group.

Seven patients underwent both the procedures in different levels.

Lateral X-ray was evaluated for radiographic assessment and we considered the height of the vertebral body measured in the middle of it, and the kyphotic deformity measured on the upper and lower end plate of the fractured vertebra.

In the vertebroplasty group (group A) the mean pre-operatively height of the vertebral body was $2.13 \mathrm{~cm}$ (range, 1.4 to $2.9 \mathrm{~cm}$ ) with a mean kyphotic deformity of $8.4^{\circ}$ (range, 0 to $13.6^{\circ}$ ). The mean post-operative height of the body in this group was $2.27 \mathrm{~cm}$ (range, 1.4 to $2.9 \mathrm{~cm}$ ), with a mean increasing value of $0.14 \mathrm{~cm}$, while the mean kyphotic correction was of $1^{\circ}$ (mean value of post-operative kyphotic deformity, $7.4^{\circ}$; range, 0 to $13.8^{\circ}$ ). In group A $46.6 \%$ of the levels had an improvement of the vertebral height with partial restoration of it, while only the $20 \%$ of it had an improvement of the kyphotic deformity.

In the kyphoplasty group (group B1 + B2) had a mean preoperative vertebral height of $1.77 \mathrm{~cm}$ (range, 0.97 to $2.32 \mathrm{~cm}$ ) with a mean kyphotic deformity of $9.7^{\circ}$ (range, 0 to $23^{\circ}$ ). The mean post-operative height of body in group B was $2.18 \mathrm{~cm}$ (range, 1.33 to $2.91 \mathrm{~cm}$ ), with a mean increasing value of $0.41 \mathrm{~cm}$, while the mean kyphotic correction was of $1.8^{\circ}$ (mean value of post-operative kyphotic defor-

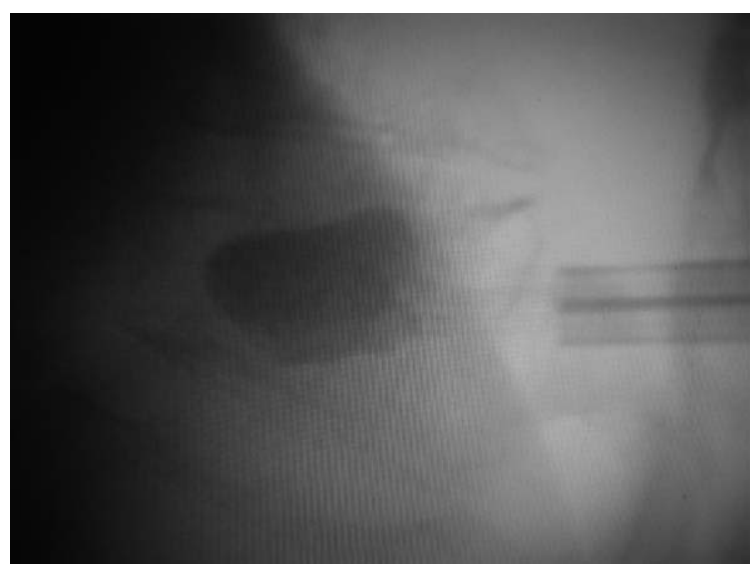

Fig. 2. Intraoperative X-rays of bipedicular kyphoplasty. mity, $7.9^{\circ}$; range, 0 to $23^{\circ}$ ). In group B, $83.3 \%$ of the levels had an improvement of the vertebral height with partial or total restoration of it and $88.8 \%$ of it had an improvement of the kyphotic deformity.

In unipedicular kyphoplasty group (B1) the amount of mean vertebral body height restored post-operative was 2.04 and in bipedicular kyphoplasty group (B2) was 2.29 but the ratio for uni- and bipedicular approach was 1.24 and 1.20 , respectively, showing not much difference while the ratio for kyphotic deformity restoration in unipedicularbipedicular kyphoplasty group was 0.74 and 0.87 , respectively.

Although we observed a better improvement of the kyphotic deformity in bipedicular kyphoplasty group, both groups had not a statistically significant improvement in the postoperative period.

We can conclude that kyphoplasty in patients affected by pathological vertebral fractures due to MM lead to a better postoperative improvement of the vertebral height and of the kyphotic deformity, with a statistical significance only for the body height restoration $(p=0.0066)$ in comparison to vertebroplasty but bipedicular kyphoplasty approach have little advantage over unipedicular approach in kyphotic deformity restoration.

The kyphotic deformity in group A observed a mean value of $7.6^{\circ}$ at 1 month and $7.7^{\circ}$ at 3 months of follow up (the postoperative mean value, $7.4^{\circ}$ ), while in group B there is a mean value of $9.0^{\circ}$ at 1 month and $8.9^{\circ}$ at 3 months (the postoperative mean value, $7.9^{\circ}$ ). We conclude that the better kyphosis correction observed postoperative in both kyphoplasty groups is lost during the first month (about $1^{\circ}$ of correction) and after that it remain unchanged at 3

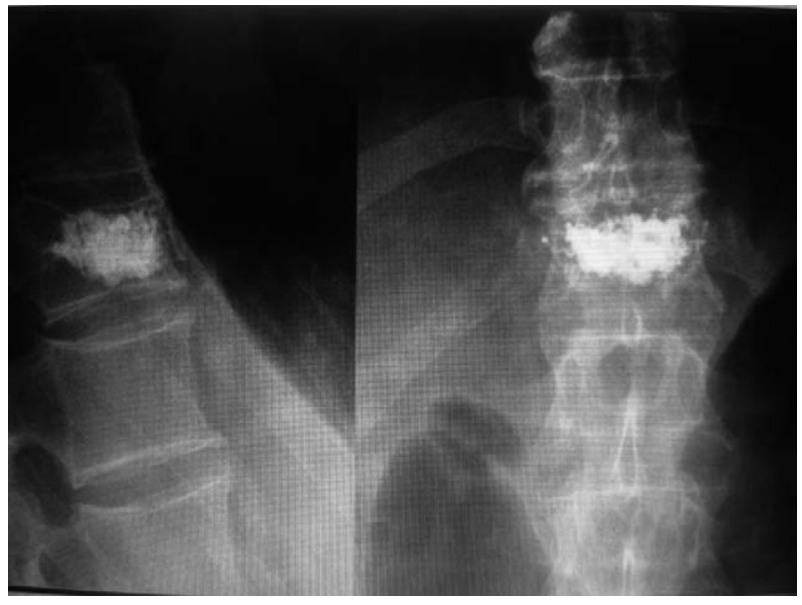

Fig. 3. Postoperative X-rays showing cement leakage anteriorly after bipedicular kyphoplasty procedure. 
months.

The $85.7 \%$ of the patients (12/14) had an immediate improvement of the pain in the postoperative period, with a mean value of VAS decreasing from 8.4 to a mean value of 4.6. The mean VAS value was 2 at three months, 1.2 at six months and 0.8 at one year of follow up. No difference between the two groups was observed regarding the pain.

We concluded that all the procedures were effective in treating the vertebral pain due to a spinal fracture in patients affected by MM.

Forty-two point eight percent of the patients (6/14) had radiographic evidence of cement leakage. Eighty percent of them $(4 / 5)$ had a multilevel treatment (three levels treatment, $\mathrm{n}=3$; two levels treatment, $\mathrm{n}=1$ ).

We observed 9 cement extravasations on 37 vertebras, that represent $24.3 \%$ of the treated levels.

The rate of cement leakage was $22.2 \%$ in vertebroplasty group while was $22.2 \%$ in monoportal kyphoplasty group and $33.3 \%$ in biportal one. No cement leakage into the canal was observed, 5 were in the paravertebral anterior space, 2 were lateral and 2 were in the disk. None of the patients had symptoms due to cement leakage (Figs. 2 and 3 ).

\section{Discussion}

Vertebral compression fractures in $\mathrm{MM}$ are present in 55$70 \%$ of patients and represent initial clinical signs in 34$64 \%$ of cases [7].

The patients usually experience severe pain and disability with a consecutive increase of morbidity [8-10] and have been traditionally treated with bed rest, bracing, radiotherapy and analgesics with limited benefit [11].

Bisphosphonates have been shown to block bone resumption and reduction of skeletal events but are unable to repair the collapse [12]. Vertebral augmentation procedures [13] are a minimally invasive surgical technique able to immediately reduce the pain and finally treat the spinal fracture.

Both procedures, vertebroplasty and kyphoplasty, are percutaneous and effective in treating the disabling pain; furthermore they allow to reinforce the vertebral body preventing further collapse as all the groups has significant improvement in VAS scores after the procedure suggesting the analgesic effect may come from immobilization of trabecular micro-fractures by cement injection [14].

Vertebroplasty is a simple injection of an acrylic polymer into the vertebral body, often done with a monoportal approach, while kyphoplasty is performed with uni- and bipedicular placement of a balloon into the vertebral body to partially restore the spinal deformity $[15,16]$.

Both procedures (vertebroplasty and kyphoplasty) were able to treat the invalidating pain of the patients, without any significant differences in between the results of two groups. The most important advantage of kyphoplasty over vertebroplasty is the ability to restore the vertebral height and to create a cavity into the vertebral body by using the inflatable balloon for the injection of a very viscous cement with very low pressure into the cavity, reducing the probability of cement leakage. Kyphoplasty is better technique to restore the vertebral height and the sagittal alignment of the vertebral body in the postoperatively lateral X-ray view, without depending on unipedicular and bipedicular approach [17].

Although during kyphoplasty in osteoporotic fractures the insertion of thick viscous cement into a pre formed cavity had resulted in a lower rate of cement extravasations in patients with osteoporotic vertebral compression fractures [18-21] but present study has $24.3 \%$ of cement extravasations may be due to high frequency of cortical breakdown by metastatic tissue as suggested by Cotten et al. [8].

In vivo comparison of extra vertebral cement leak after vertebroplasty and kyphoplasty using injection of contrast showed significantly lower extra vertebral leakage with kyphoplasty [22] but the clinical incidence of cement extravasations is much lower with kyphoplasty, reported at $4 \%$ to $9 \%$ [18]. Additionally the bipedicular approach during kyphoplasty seems to increase the risk of cement leakage in current study in contrary to results of Papadopoulos et al. [15], where low rate of cement extravasations was observed in bipedicular kyphoplasty (Table 2).

In present study also the unipedicular kyphoplasty and vertebroplasty has less chances of cement leakage than bipedicular kyphoplasty suggesting monoportal technique is safer in terms of cement leakage possibly due to low pressure fill of higher viscosity cement into the created cavity $[17,23]$. Some authors also used the eggshell technique to prevent cement leakage during kyphoplasty procedures [24].

Interestingly patients with multiple levels fracture without bone marrow transplant had a higher risk of cement extravasations.

Both techniques uni and bipedicular for kyphoplasty has comparable results in terms of kyphotic angles and restoring the vertebral height as also reported by Chung et al. [25].

Both vertebroplasty and kyphoplasty in conclusion are 
Table 2. Cement extravasation after percutaneous vertebral augmentation in spinal pathologies

\begin{tabular}{llllcc}
\hline \hline Reference & Procedure & Technique & Pathology & No. of procedures & Cement leakage in patients \\
\hline Fourney et al. [26] & $\begin{array}{l}\text { Vertebroplasty, } \\
\text { kyphoplasty }\end{array}$ & Bilateral & $\begin{array}{c}\text { Osteoblastic and mixed } \\
\text { spinal metastasis }\end{array}$ & 97 \\
Dudeney et al. [1] & Kyphoplasty & Bilateral & Multiple myeloma & 55 & 2 \\
Pflugmacher et al. [13] & Kyphoplasty & Bilateral & Osteoporosis & 64 & 8 \\
Sun et al. [17] & Kyphoplasty & Unilateral & Osteoporosis & 61 & 2 \\
\hline
\end{tabular}

effective in treating vertebral compression fracture due to MM and none has an advantage over the other in pain improvement as also evident in the study of Fourney et al. [26].

Vertebroplasty could be indicated to treat single level lesion especially in the thoracic spine while unipedicular kyphoplasty has better results in multiple levels collapse.

Unipedicular kyphoplasty provides equally good results for maintaining sagittal alignment of the spine and restoring the height of the vertebral body especially at the thoracolumbar spinal segment in comparison to bipedicular kyphoplasty with less chance of neoplastic tissue migration into the canal [27]. Also monolateral approach has less operative time, less radiation exposure and cost effectiveness to treat MM vertebral lesions as also observed by Steinmann et al. [16].

This study has some limitations regarding the less number of patients and lack of proper indication for different technique. There is a need for larger series of patients for prospective analysis regarding unipedicular and bipedicular technique outcome.

\section{Conclusions}

Unilateral kyphoplasty technique has equally good potential to treat multiple myeloma vertebral lesions with lesser number of complications in comparision to bipedicular kyphoplasty approach.

\section{REFERENCES}

1. Dudeney S, Lieberman IH, Reinhardt MK, Hussein M. Kyphoplasty in the treatment of osteolytic vertebral compression fractures as a result of multiple myeloma. J Clin Oncol 2002;20:2382-7.

2. Lecouvet FE, Vande Berg BC, Maldague BE, et al. Vertebral compression fractures in multiple myeloma. Part I. Distribution and appearance at MR imaging. Radiology 1997;204:195-9.
3. Galibert P, Deramond H, Rosat P, Le Gars D. Preliminary note on the treatment of vertebral angioma by percutaneous acrylic vertebroplasty. Neurochirurgie 1987;33:166-8.

4. Lane JM, Hong R, Koob J, et al. Kyphoplasty enhances function and structural alignment in multiple myeloma. Clin Orthop Relat Res 2004;(426):49-53.

5. Masala S, Anselmetti GC, Marcia S, Massari F, Manca A, Simonetti G. Percutaneous vertebroplasty in multiple myeloma vertebral involvement. J Spinal Disord Tech 2008;21:344-8.

6. McDonald RJ, Trout AT, Gray LA, Dispenzieri A, Thielen KR, Kallmes DF. Vertebroplasty in multiple myeloma: outcomes in a large patient series. AJNR Am J Neuroradiol 2008;29:642-8

7. Ramos L, de Las Heras JA, Sánchez S, et al. Medium-term results of percutaneous vertebroplasty in multiple myeloma. Eur J Haematol 2006;77:7-13.

8. Cotten A, Dewatre F, Cortet B, et al. Percutaneous vertebroplasty for osteolytic metastases and myeloma: effects of the percentage of lesion filling and the leakage of methyl methacrylate at clinical follow-up. Radiology 1996;200:525-30.

9. Lad SP, Patil CG, Lad EM, Boakye M. Trends in pathological vertebral fractures in the United States: 1993 to 2004. J Neurosurg Spine 2007;7:305-10.

10. Lunt M, O'Neill TW, Felsenberg D, et al. Characteristics of a prevalent vertebral deformity predict subsequent vertebral fracture: results from the European Prospective Osteoporosis Study (EPOS). Bone 2003;33:505-13.

11. Lecouvet F, Richard F, Vande Berg B, et al. Long-term effects of localized spinal radiation therapy on vertebral fractures and focal lesions appearance in patients with multiple myeloma. Br J Haematol 1997;96:743-5.

12. Berenson JR, Lichtenstein A, Porter L, et al. Efficacy of pamidronate in reducing skeletal events in patients with advanced multiple myeloma. Myeloma Aredia Study Group. N Engl J Med 1996;334:488-93.

13. Pflugmacher R, Taylor R, Agarwal A, et al. Balloon kyphoplasty in the treatment of metastatic disease of the 
spine: a 2-year prospective evaluation. Eur Spine J 2008; 17:1042-8.

14. Weill A, Chiras J, Simon JM, Rose M, Sola-Martinez T, Enkaoua E. Spinal metastases: indications for and results of percutaneous injection of acrylic surgical cement. Radiology 1996;199:241-7.

15. Papadopoulos EC, Edobor-Osula F, Gardner MJ, Shindle MK, Lane JM. Unipedicular balloon kyphoplasty for the treatment of osteoporotic vertebral compression fractures: early results. J Spinal Disord Tech 2008;21:589-96.

16. Steinmann J, Tingey CT, Cruz G, Dai Q. Biomechanical comparison of unipedicular versus bipedicular kyphoplasty. Spine (Phila Pa 1976) 2005;30:201-5.

17. Sun G, Jin P, Li FD, et al. Preliminary study on a single balloon cross-midline expansion via unipedicular approach in kyphoplasty. Chin Med J (Engl) 2008;121:1811-4.

18. Lieberman IH, Dudeney S, Reinhardt MK, Bell G. Initial outcome and efficacy of "kyphoplasty" in the treatment of painful osteoporotic vertebral compression fractures. Spine (Phila Pa 1976) 2001;26:1631-8.

19. Bouza C, López T, Magro A, Navalpotro L, Amate JM Efficacy and safety of balloon kyphoplasty in the treatment of vertebral compression fractures: a systematic review. Eur Spine J 2006;15:1050-67.

20. Gill JB, Kuper M, Chin PC, Zhang Y, Schutt R Jr. Comparing pain reduction following kyphoplasty and vertebroplasty for osteoporotic vertebral compression fractures.
Pain Physician 2007;10:583-90.

21. Hulme PA, Krebs J, Ferguson SJ, Berlemann U. Vertebroplasty and kyphoplasty: a systematic review of 69 clinical studies. Spine (Phila Pa 1976) 2006;31:1983-2001.

22. Phillips FM, Todd Wetzel F, Lieberman I, Campbell-Hupp M. An in vivo comparison of the potential for extravertebral cement leak after vertebroplasty and kyphoplasty. Spine (Phila Pa 1976) 2002;27:2173-8.

23. Eck JC, Nachtigall D, Humphreys SC, Hodges SD. Comparison of vertebroplasty and balloon kyphoplasty for treatment of vertebral compression fractures: a meta-analysis of the literature. Spine J 2008;8:488-97.

24. Greene DL, Isaac R, Neuwirth M, Bitan FD. The eggshell technique for prevention of cement leakage during kyphoplasty. J Spinal Disord Tech 2007;20:229-32.

25. Chung HJ, Chung KJ, Yoon HS, Kwon IH. Comparative study of balloon kyphoplasty with unilateral versus bilateral approach in osteoporotic vertebral compression fractures. Int Orthop 2008;32:817-20.

26. Fourney DR, Schomer DF, Nader R, et al. Percutaneous vertebroplasty and kyphoplasty for painful vertebral body fractures in cancer patients. J Neurosurg 2003;98(1 Suppl):21-30.

27. Carrino JA, Chan R, Vaccaro AR. Vertebral augmentation: vertebroplasty and kyphoplasty. Semin Roentgenol 2004;39:68-84. 